\title{
Intertidal molluscan and algal species richness around the UK coast
}

\author{
Andrew J. Blight ${ }^{1, *}$, A. Louise Allcock ${ }^{1,2}$, Christine A. Maggs ${ }^{1,2}$, Mark P. Johnson ${ }^{1,2}$ \\ ${ }^{1}$ School of Biological Sciences, Queen's University Belfast, Medical Biology Centre, 97 Lisburn Road, Belfast, BT9 7BL, UK \\ ${ }^{2}$ The Martin Ryan Marine Science Institute, National University of Ireland, University Road, Galway, Ireland
}

\begin{abstract}
Geographically referenced databases of species records are becoming increasingly available. Doubts over the heterogeneous quality of the underlying data may restrict analyses of such collated databases. We partitioned the spatial variation in species richness of littoral algae and molluscs from the UK National Biodiversity Network database into a smoothed mesoscale component and a local component. Trend surface analysis (TSA) was used to define the mesoscale patterns of species richness, leaving a local residual component that lacked spatial autocorrelation. The analysis was based on $10 \mathrm{~km}$ grid squares with 115035 records of littoral algae (729 species) and 66879 records of littoral molluscs (569 species). The TSA identified variation in algal and molluscan species richness with a characteristic length scale of approximately $120 \mathrm{~km}$. Locations of the most speciesrich grid squares were consistent with the southern and western bias of species richness in the UK marine flora and fauna. The TSA also identified areas which showed significant changes in the spatial pattern of species richness: breakpoints, which correspond to major headlands along the south coast of England. Patterns of algal and molluscan species richness were broadly congruent. Residual variability was strongly influenced by proxies of collection effort, but local environmental variables including length of the coastline and variability in wave exposure were also important. Relative to the underlying trend, local species richness hotspots occurred on all coasts. While there is some justification for scepticism in analyses of heterogeneous datasets, our results indicate that the analysis of collated datasets can be informative.
\end{abstract}

KEY WORDS: Hotspot · Headland - Trend surface analysis $\cdot$ Mesoscale $\cdot$ Autocorrelation $\cdot$ Local · Regional Resale or republication not permitted without written consent of the publisher

\section{INTRODUCTION}

While broad latitudinal gradients have traditionally been a focus of biodiversity research, there are also mesoscale patterns of variation in species richness that are less well characterized $\left(10^{1}\right.$ to $10^{6} \mathrm{~km}^{2}$; Harrison \& Cornell 2008). Such mesoscale patterns are important, as they interact with the typical dispersal scales of marine organisms (median $20 \mathrm{~km}$, interquartile range

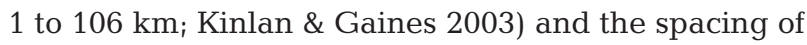
protected areas (median $21 \mathrm{~km}$ nearest neighbour distance, interquartile range 13 to $37 \mathrm{~km}$; Johnson et al. 2008). Examples of variability in species richness include areas of high (or low) species richness, the variation be- ing associated with features such as large estuaries and abrupt changes or 'breakpoints' in species richness. For the UK, a variety of regional features have been proposed (e.g. Crisp \& Southward 1958, Lewis 1964, Briggs 1974, Lüning 1990). With the recent development of biodiversity data servers (e.g. the National Biodiversity Network [NBN] Gateway, http://data.nbn.org.uk/) it is now possible to revisit earlier work and examine the spatial patterns in a statistical model-fitting framework. Spatially explicit analyses of this sort are an important component of sustainability planning in marine spatial management programmes (Ehler \& Douvere 2009).

Patterns of species diversity typically vary at multiple scales, reflecting the different processes involved 
(Levin 1992, Willis \& Whittaker 2002). Ideally one could separate out the components at different scales to gain a greater understanding of pattern. Unfortunately, 2 issues limit this approach: (1) processes at different scales are unlikely to be completely independent and cross-scale interactions occur (e.g. Gouhier \& Guichard 2007); (2) methods such as spectral and wavelet analysis can be used to examine patterns at different scales, but each method has limitations (Saunders et al. 2005). In the context of species richness values along a coastline, the data are not in a regular unbroken sequence and are therefore unsuited to wavelet or spectral analyses. A practical solution to the multiscale nature of species diversity is to examine the patterns at a limited number of discrete scales. This approach is often associated with nested studies, where the allocation of effort can be standardized (Rivadeneira et al. 2002). A typical contrast has been one between regional and local diversity (Ricklefs 1987). In the present study, we made the same contrast, but the relationship between local and regional is defined using a regression-based smoother rather than by pooling samples. For consistency, we refer to the larger scale variation estimated by the regression-based smoother as regional or mesoscale variability. Local variation then refers to the pattern of residual variation at the $10 \mathrm{~km}$ grid scale. Regression-based smoothing avoids the correlation between local and regional richness that confounds many studies (Hillebrand \& Blenckner 2002).

Data quality potentially influences the perceived spatial variation of biodiversity in datasets collated over many surveys. Survey effort varies due to the number of visits to particular areas, among other possible sources of variation such as the identification skills of observers. Our initial observations of the spatial patterns in untransformed species richness show peaks in the data that correspond to the major marine research stations around the UK. As abundance information and details of methodology were frequently absent in the collated dataset, it was not possible to attempt a correction for effort with a rarefaction procedure. The approach taken in the present study was not to correct the data prior to exploration, but to test for associations with proxies of collection effort following model fitting. We anticipated that variation in collection effort is a relatively local-scale process so that this variation will affect the residual pattern more strongly than the smoothed species richness. To test this idea we compared the spatial autocorrelation functions of smoothed data and collection effort, with a prediction that the spatial extent of autocorrelation will be greater in the smoothed data. We also predicted that variation in collection effort will have a significant effect on residual species richness. Other variables are likely to influence local species richness, including mean wave exposure, length of coastline and variance in wave exposure. Associations between species richness and these additional predictor variables were examined in exploratory regression analyses.

In summary, the present study examined the spatial patterns in species richness of intertidal algae and molluscs around the coast of the UK. The spatial variation in species richness was partitioned, using a spatial smoothing function, into a mesoscale component and a residual component. In addition to a description of the mesoscale pattern, we present an identification of the sharpest transitions in species richness between grid squares. The residual components of species richness were compared to proxies of collection effort and other abiotic influences to indentify sources of variation in recorded local species richness.

\section{METHODS}

Database construction. The NBN Gateway was accessed to retrieve data on UK marine surveys from a variety of sources. These sources included the Marine Nature Conservation Review (MNCR) dataset compiled by the Joint Nature Conservation Committee (JNCC), Countryside Council for Wales (CCW) and Scottish National Heritage (SNH); the British Phycological Society (BPS) dataset; the Conchological Society of Great Britain and Ireland (ConchSoc) dataset; the Marine Life Information Network (MarLIN) dataset (both professional and volunteer); the Northern Ireland Littoral Survey (NILS) dataset; the Marine Conservation Society (MCS) Seasearch Marine Surveys and the Pembrokeshire Tide Influenced Communities dataset. The records were accessed and collated between March and May 2006 and periodically updated throughout 2007. These data included species richness (presence/absence) at a resolution of $10 \times 10 \mathrm{~km}$ grid squares. Each grid square had a geographic coordinate based on its position in the Ordnance Survey (OSGB) grid system. Analyses were focused on patterns for littoral molluscs and algae, as these are the 2 most widely recorded groups and molluscs have been shown to act as surrogates for broader patterns in littoral assemblages (Smith 2005).

The NBN data included both littoral and sublittoral records and were filtered to produce littoral-only fauna and flora. Where information on record shore height was missing, site records were allocated to an appropriate level through a comparison of the list of species at that site against a list of known littoral/sublittoral species. These test species were drawn from complete records, provided they were found in their corresponding zone on more than $99 \%$ of occasions and had at 
least 50 records in the database. All subsequent statistical analysis was carried out on littoral species richness data.

Spatial analysis of pattern. The subdivision of species richness patterns into a regional and local component was carried out using trend surface analysis (TSA). This is the oldest technique applied for producing smoothed maps (Legendre \& Legendre 1998) and involves fitting a polynomial equation based on the geographic coordinates to the dependent variable (species richness in a $10 \times 10 \mathrm{~km}$ grid square). Nonsignificant terms are removed from the polynomial by backwards elimination to produce the most parsimonious model (Legendre \& Legendre 1998). The smoothing process emphasizes spatial gradients in richness and can be thought of as the regional signal. As the model-fitting process is not constrained by a particular expectation, the resultant regional pattern could be a latitudinal gradient or a more complex set of features. As well as a visual examination of the pattern in the smoother, the typical length scale of richness patterns in the intertidal was estimated using spatial autocorrelation. The smoother is anticipated to be less sensitive to changes in species richness that are related to local collection effort, so relatively abrupt changes in the predicted species richness were used to define the positions of breakpoints (sudden transitions in species richness). The mean change in species richness between adjacent squares was 2.28 for molluscs and 3.33 for algae. Transitions greater than the mean + $1 \mathrm{SD}$ for each taxonomic group (molluscs $=4.29$; algae $=4.37$ ) highlighted large environmental or habitat changes such as major estuaries, cities, headlands or large islands, particularly those along the south coast of England and the west of Scotland. There were 50 transitions exceeding the mean $+\mathrm{SD}$ criterion for molluscs and 47 cases for algae. Though of regional interest, the relatively high number of mean + SD transitions may contain false positives and merits further investigation. For simplicity, we concentrated on the most extreme changes in species richness between grid squares. There were 3 changes in species richness between grid squares ( 4 for molluscs) that were outliers in terms of the magnitude of the transition (exceeding a change of 20 for mollusc species richness and 22 for algal species richness). These transition points are presented as breakpoints representing the largest grid square-grid square transitions in the smoothed data.

Having removed a mesoscale signal by fitting a trend surface, the remaining signal is contained in the residuals. This local signal was expected to reflect variation between $10 \mathrm{~km}$ squares in habitat and collection effort. The influences of the additional predictor variables of collection effort, wave exposure, variance in wave exposure and coastline length were examined using multiple regression. The total number of records and the number of different record dates recorded in a grid square were taken as proxies for collection effort. For a first approximation, coastline length and variance in wave exposure were assumed to be measures of habitat diversity. A relatively long coastline length within a grid square implies indentations in the coastline, potentially leading to a diversity of habitats. Similarly, if a grid square has a relatively high variation in exposure, this implies a diversity of exposed and sheltered habitats. Wave exposure values were taken from the dataset produced by Burrows et al. (2008). Values are based on total fetch and are calculated at a spacing of every $200 \mathrm{~m}$ around the coast of the UK. Variables were natural log-transformed before model fitting, as examination of residual plots suggested this was appropriate. Wave exposure data were transformed using $x^{0.277}$, as a plot of variance against mean suggested that this transformation would minimize the dependency between the mean and variance (Legendre \& Legendre 1998).

Trend surface fitting was carried out in the SAM software package (Rangel et al. 2006). An information theoretic approach based on comparisons of Akaike's information criterion (AIC) was used to choose an optimum level of complexity in multiple regression analyses (Burnham \& Anderson 2004). The lowest value of AIC in a set of models defines the model with the best fit for the lowest level of model complexity. AIC values were also used in an averaging process when examining the influence of the potential predictor values on species richness. This averaging approach reflects the practicalities of comparing models that may have similar predictive power, such that a choice of the 'best' model may discard information in related models. When models are compared using AIC as a measure of fit, each model can be compared to the best model (lowest $\mathrm{AIC}$ ) and given a weighting, equivalent to a probability that the model is the best one in the set of candidate models (Johnson \& Omland 2004). The probability weighting based on relative AIC values reflects the origin of AIC in maximum likelihood theory and is known as an Akaike weight. Comparisons of Akaike weights among different models highlight the more consistently influential predictor variables. A more formal comparison of alternative predictor variables is made by comparing a quantity known as the average importance. The average importance of each variable is the sum of Akaike weights for all models containing that variable (Burnham \& Anderson 2004). A high importance (up to a maximum of 1) for a variable therefore indicates that it occurred in the most powerful predictive models. We therefore present model comparisons using the average importance for 
different predictor variables, alongside AIC values as a measure of model fit. Comparisons of AIC values used the small sample corrected version of the information criterion, $\mathrm{AIC}_{\mathrm{C}}$.

\section{RESULTS}

There are 852 squares of $10 \mathrm{~km}$ around the UK that include a stretch of coastline. For 615 of these squares, there were records of littoral algae, with 642 having information on littoral molluscs. Most of the surveyed squares with no littoral species records were along the east coast of England and Scotland, particularly Suffolk, Norfolk, Lincolnshire, Angus and Kincardineshire. These grid squares were treated as missing values rather than zeroes. There were 115035 entries for littoral algae around the UK, consisting of a total of 729 species, and 66879 entries for littoral molluscs with a total of 569 species.

Trend surface fits for first order polynomials demonstrated significant south-north and west-east declines in predicted species richness for both algae and molluscs. A simple linear decline with distance from the southwest was not a sufficient descriptor of the pattern, judging from the lower $\mathrm{AIC}_{\mathrm{c}}$ values for more complex polynomial trend surfaces (Table 1). Final trend surfaces had 17 predictor variables for algae and 22 for molluscs. The fitted trend surfaces are a smoothed representation of the raw data, so it is unsurprising that

Table 1. Comparative trend surface model-fitting results for surfaces of increasing complexity. All terms were fitted in the polynomial models except the optimum, which was reached by backwards elimination of non-significant terms. All fitted models were statistically significant at $\mathrm{p}<0.05$. $\mathrm{AIC}_{\mathrm{c}}$ : corrected Akaike's information criterion

\begin{tabular}{|lcrrc|}
\hline $\begin{array}{l}\text { Response variable } \\
\text { Fitted model }\end{array}$ & $\mathrm{r}^{2}$ & $F$ & $\mathrm{AIC}_{\mathrm{c}}$ & $\begin{array}{c}\text { Predictor } \\
\text { variables }\end{array}$ \\
\hline \multicolumn{2}{l}{ Molluscan species richness $(\mathrm{n}=$} & $642)$ & & \\
1st order polynomial & 0.031 & 10.3 & 1899.7 & 2 \\
2nd order polynomial & 0.088 & 12.3 & 1866.8 & 5 \\
3rd order polynomial & 0.139 & 11.4 & 1838.2 & 9 \\
4th order polynomial & 0.203 & 11.4 & 1799.4 & 14 \\
5th order polynomial & 0.252 & 10.5 & 1770.7 & 20 \\
6th order polynomial & 0.284 & 9.0 & 1757.9 & 27 \\
Optimum model & 0.282 & 11.1 & 1749.1 & 22 \\
& & & & \\
Algal species richness (n & $=615)$ & & & \\
1st order polynomial & 0.024 & 7.4 & 1869.2 & 2 \\
2nd order polynomial & 0.083 & 11.1 & 1836.3 & 5 \\
3rd order polynomial & 0.137 & 10.7 & 1807.3 & 9 \\
4th order polynomial & 0.205 & 11.1 & 1767.4 & 14 \\
5th order polynomial & 0.240 & 9.4 & 1752.6 & 20 \\
6th order polynomial & 0.250 & 7.2 & 1759.8 & 27 \\
Optimum model & 0.236 & 10.9 & 1749.1 & 17 \\
\hline
\end{tabular}

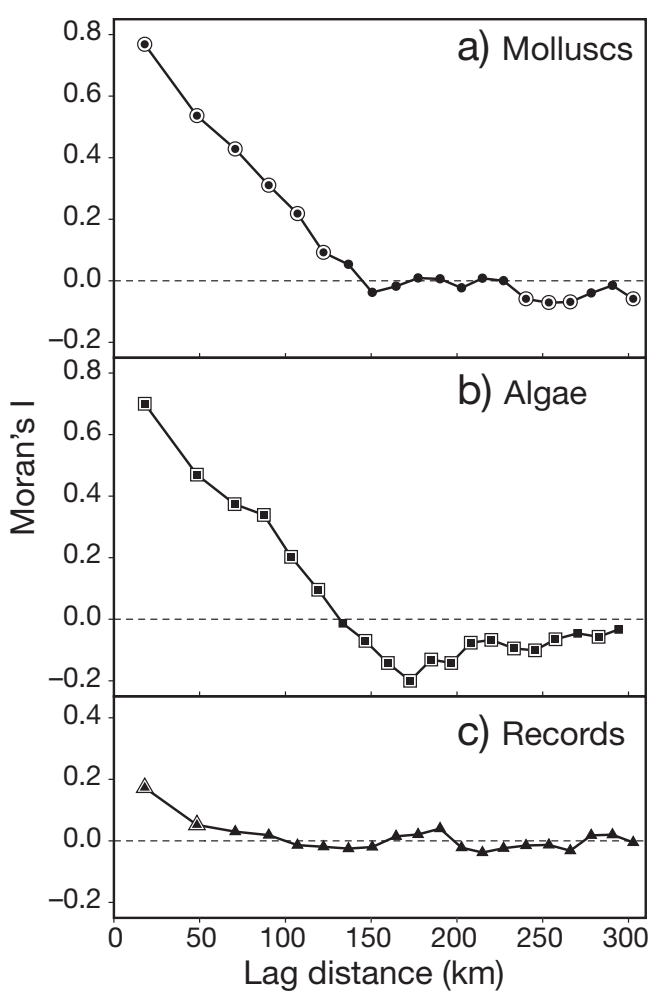

Fig. 1. Spatial autocorrelation (Moran's $I$ ) in the trend surface modelled for (A) molluscan species richness, (B) algal species richness and $(\mathrm{C})$ records per grid cell. Symbols with a border represent significant autocorrelation at the related lag distance $(p<0.05)$, following a Bonferroni correction for multiple tests within each correlogram

predicted species richness values for algae and molluscs are autocorrelated (Fig. 1). Positive autocorrelation extended to approximately $120 \mathrm{~km}$ in algae and molluscs. The autocorrelation function is a mesoscale summary of spatial pattern, suggesting that, on average, the length scale for areas of relatively high or low species richness was about $120 \mathrm{~km}$. The spatial patterns in fitted mollusc and algal species richness were more defined than those for collection effort. The autocorrelation of record numbers extended over approximately $50 \mathrm{~km}$. Residuals from the trend surface analyses had no pattern of spatial autocorrelation.

The smoothed patterns of species richness for algae and molluscs were broadly congruent $(\mathrm{r}=0.582, \mathrm{df}=$ $270.3, p<0.001$; note that $d f$ is not in integer form, as the Dutilleul 1993 method was used to correct for spatial autocorrelation), with some small differences (Fig. 2). For molluscs, the most diverse squares were along the south coast of England, the Scilly Isles and in the Inner Hebrides, particularly around the Isle of Skye. Reducing the cut-off percentage from the top $10 \%$ to the top $5 \%$ of grid squares emphasized the richness of the south coast of England and the Scilly Isles. Algae were also diverse along the south and 


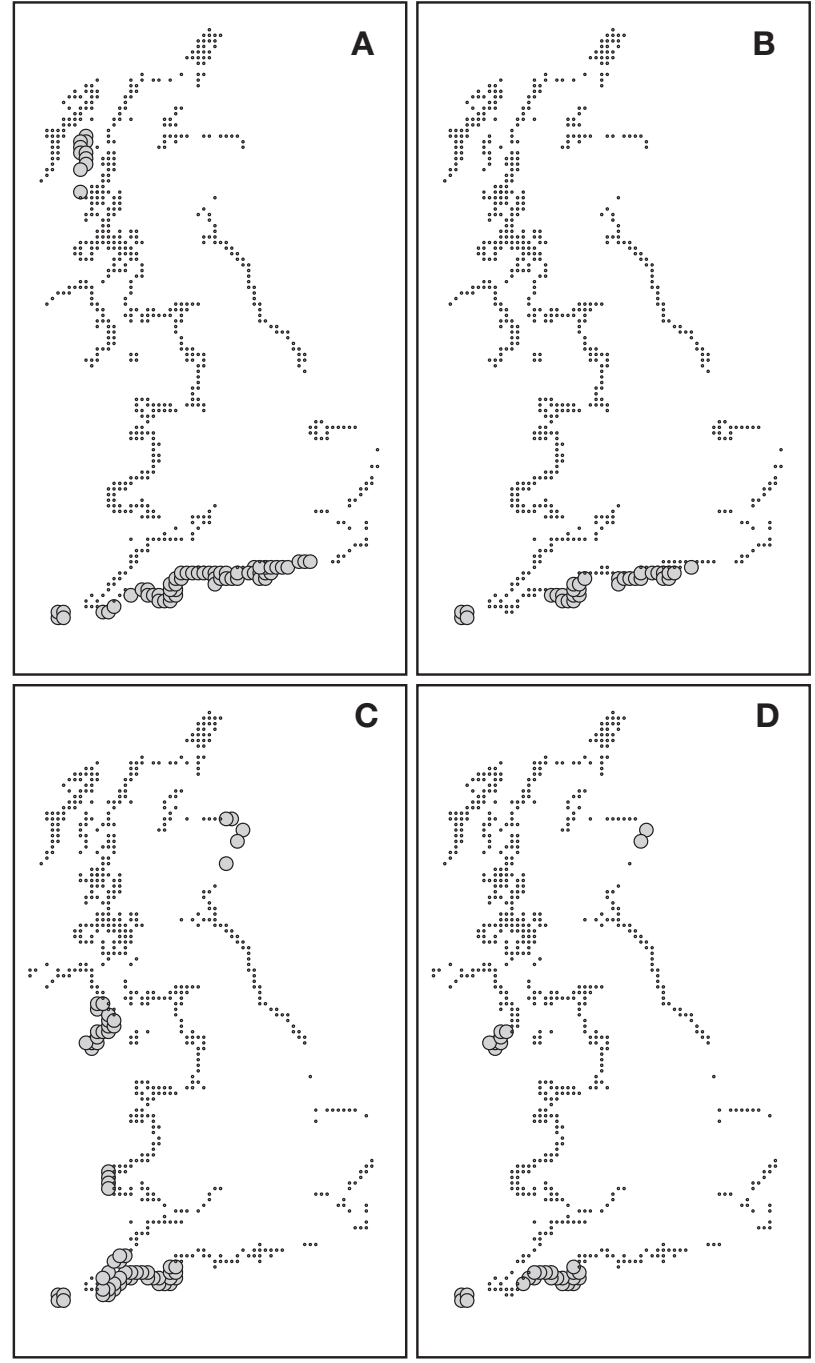

Fig. 2. Spatial patterns of $(A, B)$ molluscan and $(C, D)$ algal species richness around the UK in the fitted trend surfaces. Symbols are scaled to emphasize areas with high predicted species richness. Dots represent $10 \mathrm{~km}$ grid squares where the corresponding taxon has been recorded. Large circles are given where a $10 \mathrm{~km}$ grid square falls within the most diverse squares in the database. Threshold values for the larger symbols are set to emphasize different cut-off points - $(\mathrm{A}, \mathrm{C})$ most diverse $10 \%$ of $10 \mathrm{~km}$ squares, $(\mathrm{B}, \mathrm{D})$ most diverse $5 \%$ of $10 \mathrm{~km}$ squares

southwestern coasts of England and the Scilly Isles, with additional areas of relatively high richness in southwest Wales, Northern Ireland and the east coast of Scotland.

The largest square-square transitions in species richness occurred between the Scilly Isles and Cornwall and along the southern coast of England (Fig. 3). These breakpoints represent drops in species richness moving eastwards from the Isles of Scilly and in the region of Start Point, Devon. There was also a sudden
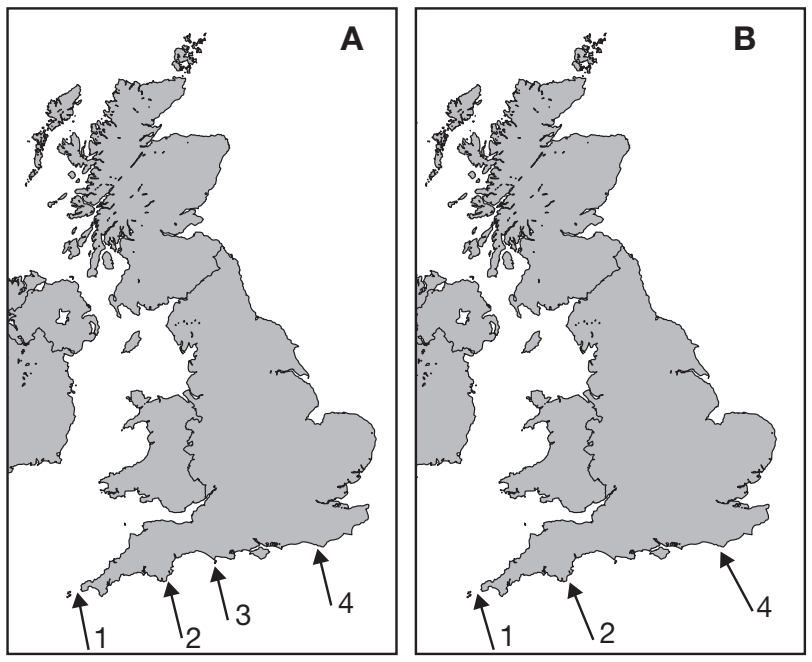

Fig. 3. Locations of the largest changes in species richness (breakpoints) between adjacent $10 \mathrm{~km}$ grid squares for (A) molluscs and (B) algae: (1) Isles of Scilly and Cornwall, (2) Start Point, (3) Portland Bill and (4) Beachy Head. Moving from west to east, the patterns are: $(1,2)$ sharp decrease in species richness; $(3,4)$ sharp increase and then decrease in species richness

increase and subsequent drop in algal species richness around Beachy Head, Sussex. There was a similar rise and fall in species richness of molluscs in the region of Portland, Dorset.

The residual (local) variation in species richness around the fitted trend surfaces was related to collection effort proxies and local habitat variables, with the best-fitted model explaining a high proportion of the

Table 2. Model averaging results for variation in the trend surface analysis residuals for molluscan and algal species richness. A total of 31 models were compared, using Akaike weights to estimate the relative importance of different predictors and weighted average coefficient values. The best model for molluscs had 4 predictor variables with a corrected Akaike's information criterion $\left(\mathrm{AIC}_{\mathrm{c}}\right)$ of 1042 and an $\mathrm{r}^{2}$ of 0.65 . The best model for algae also had the same 4 predictor variables with an $\mathrm{AIC}_{\mathrm{c}}$ of 990 and an $\mathrm{r}^{2}$ of 0.70

\begin{tabular}{|lccc|}
\hline $\begin{array}{l}\text { Predictor } \\
\text { variable }\end{array}$ & Importance & $\begin{array}{c}\text { Standardized } \\
\text { coefficient }\end{array}$ & $\begin{array}{c}\text { In best } \\
\text { model? }\end{array}$ \\
\hline Molluscan species richness & & \\
Dates & 0.951 & -0.106 & $\mathrm{Y}$ \\
Records & 1 & 0.867 & $\mathrm{Y}$ \\
Mean exposure & 0.477 & -0.04 & $\mathrm{~N}$ \\
Variance of exposure & 0.606 & -0.044 & $\mathrm{Y}$ \\
Coastline length & 0.759 & 0.059 & $\mathrm{Y}$ \\
& & & \\
Algal species richness & & & \\
Dates & 0.89 & -0.089 & $\mathrm{Y}$ \\
Records & 1 & 0.886 & $\mathrm{Y}$ \\
Mean exposure & 0.419 & -0.038 & $\mathrm{~N}$ \\
Variance of exposure & 0.996 & -0.1 & $\mathrm{Y}$ \\
Coastline length & 0.966 & 0.087 & $\mathrm{Y}$ \\
\hline
\end{tabular}


residual variation $\left(\mathrm{r}^{2}=0.65\right.$ for molluscs, 0.70 for algae; Table 2). Proxies for collection effort were the most important variables, particularly the total number of records within a grid square. While the number of records had a positive effect on the number of species recorded, the number of survey dates had a weaker negative effect on the recorded richness. Coastline length had a positive effect on species richness and was generally the most important of the habitat variables examined. Exposure variables (mean and variance) had negative effects on species counts from grid squares. The importance of coastline and exposure variables in the averaged models indicates that the local variation in species richness was driven by more than just variability of sampling effort.

\section{DISCUSSION}

Fitting a trend surface to the dataset emphasizes the mesoscale variability in species richness around the coastline. Latitudinal gradients exist within the overall patterns, but their strength is altered at regional scales by other features, such as the response to large estuaries or areas of less species-rich habitat (Hillebrand 2004). The mesoscale features in the UK species richness dataset do not appear to be driven by collection effort, as the available proxies for collection show concentration of effort at smaller spatial scales. There was a marked influence of collection effort on the residual variation in species richness at grid square scales. Habitat variables, however, also had predictive power at these scales, implying that local variation in species richness may be influenced by variables such as habitat heterogeneity or area within a $10 \mathrm{~km}$ square.

The analyses presented in the present study differ from previous research in the source of distribution data. Desk-based studies have often used range limit data to define the richness in different areas (e.g. Macpherson 2002). This approach potentially biases patterns of species richness to the centre of the region considered, and does not contain data on gaps in species' distributions (Gaines \& Lubchenco 1982). Ideally, patterns of variation in diversity would be defined from standardized surveys, reducing the potential for collection effort and other biases to influence the results. Unfortunately, the resources to carry out such surveys will always be limited. It is not surprising that the authors of large replicated studies of biodiversity describe the survey work as 'unprecedented' (Schoch et al. 2006, Blanchette et al. 2008). The database record approach presented in the present study emphasizes some of the same information that intensive field surveys can show. For example, Blanchette et al. (2008) concluded that biogeographical regions along the
Pacific coast of North America were separated by changes in coastline orientation and/or stretches of unfavourable habitat, a situation similar to the breakpoints identified along the southern coastline of England. The advantage with collating data from species records is that the analysis uses contiguous grid squares at a relatively fine resolution $(10 \mathrm{~km})$. This adds greater resolution to the identification of pattern when compared to field surveys that may have average separations between sites exceeding $70 \mathrm{~km}$ (Bustamante \& Branch 1996, Blanchette et al. 2008). The disadvantage of using collated records is that sampling is not standardized; therefore, habitat-specific associations may be lost and analyses using abundance as well as species presence are not possible. Furthermore, using collated records introduced uncontrolled biases and errors in the spatial distribution of effort and skill.

The main proxies for collection effort in the present study were number of records and number of separate record dates. Not surprisingly, species richness was positively associated with collection effort proxies. For molluscs, the number of records was correlated with both the fitted TSA $(r=0.378)$ and the residuals from the TSA $(r=0.799)$. Equivalent correlations for algal richness were 0.467 for the smoothed surface and 0.822 for the residuals. Associations with collection effort were therefore much stronger in the residual pattern, implying that collection effort had a greater influence at the $10 \mathrm{~km}$ scale than in the smoothed patterns of the trend surface. As shown in Fig. 1, the TSA identifies features that extend over $100 \mathrm{~km}$, while collection effort extends over a range of about $50 \mathrm{~km}$. This implies that patches of high richness grid squares driven by phenomena such as the presence of a marine laboratory extend over a smaller area than the features identified by the trend surface. Taken together, the spatial autocorrelation evidence and relative strength of correlations coefficients both suggest that the smoothed data is less influenced by collection effort than the residual pattern and that the smoothed pattern therefore represents more than an artefact of historical sampling effort.

The causes of the mesoscale regional patterns of molluscs and algae are difficult to separate. Climate certainly plays a role. For example, the peak in mollusc species richness in the Inner Hebrides may reflect the warmer winters in the west and northwest of Scotland than in southern parts of the North Sea (Lewis et al. 1982). Habitat also seems likely to play a role, with regions of high diversity generally found away from estuaries (Burrows et al. 2008) or areas with extensive soft sediment. While habitat heterogeneity at $10 \mathrm{~km}$ grid cell scales (coastline length as a proxy) affected species richness (see also Archambault \& Bourget 1996), the covari- 
ance of climate makes it difficult to estimate the role of heterogeneity at larger scales. So it is unclear whether mesoscale species diversity is reduced as a result of the much less indented east coast of Great Britain when compared to the more complex west coast.

It is not clear why there should be a region of increased algal richness on the east coast of Scotland. This pattern does not appear to be associated with a particularly high collection effort. It may be that the quality of surveys in this area is relatively high, leading to more species per record. It is also relevant that the spacing of grid squares with records in this region is relatively sparse, so that the regional smoother is more influenced by the values from individual grid squares than elsewhere in the dataset.

Alternative methods of providing a smoother are possible: for example generalized additive models (GAMs) or a moving window. These methods do not suggest method-specific influences on the pattern identified. Fitted smoothers tended to produce very similar results to the trend surface analysis, with correlations between fitted values exceeding 0.88 (based on GAMs fitted with estimated df of 34.4 and 24.6 for molluscs and algae, respectively, and a square moving window of $13 \times 13$ grid squares).

The analyses in the present study are relevant to conservation-related attempts to define species diversity hotspots (Hiscock \& Breckels 2007). There are no criteria for the deviation from the mean required to define a site as a hotspot. The fitted distributions for species richness were skewed to the right and we used a simple proportional approach to identify the most species-rich sites. By separating the spatial pattern into a regional and a local component, 2 levels can be used to define a hotspot. In Fig. 2, regions are shown to be species-rich (hotspot regions) or not. The residual score shows whether a grid square has relatively high or low species richness in comparison to the average species richness of that region. The more extreme residuals are scattered around the coastline. We extended this approach by making a correction for the number of records and using the residuals from this relationship to identify outlying grid squares of interest (Fig. 4). High richness regions do not generally contain further grid squares that are effort-corrected hotspots of relatively high diversity. If anything, the high diversity regions are more likely to contain local relative 'coldspots' of reduced diversity, although this is mostly an artefact of introducing a second predictor variable correlated to the TSA. What such analyses can do, however, is to highlight grid squares that may be of interest for conservation planning or further investigation.

An example of how different processes shape the relative variation in species richness can be given using the local estuarine hotspots (Fig. 4). There are at

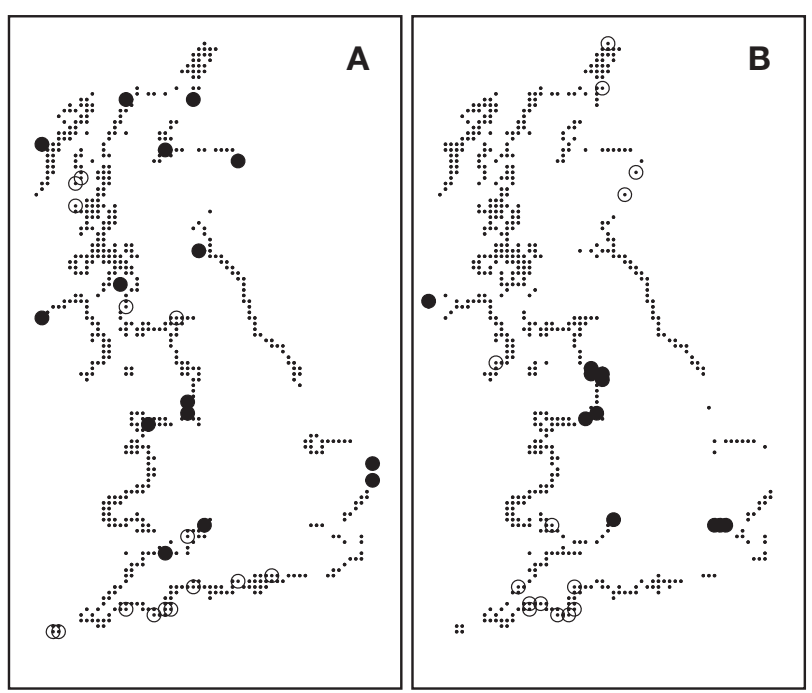

Fig. 4. Residual patterns of species richness following removal of the trend surface component in (A) molluscs and (B) algae. Large symbols are outliers falling in the upper or lower $5 \%$ of residual values following a regression to control for variation in record number within each $10 \mathrm{~km}$ square.

(๑) relatively high species richness hotspots; $(\odot)$ relatively low species richness, 'cool spots'

least 3 hypotheses for why a $10 \mathrm{~km}$ square in an estuary may have relatively more species than the adjacent squares: (1) there may be a habitat such as an outcrop of rocky shore that adds to the local diversity compared to surrounding intertidal mud (this habitat may be artificial, such as marinas or harbour walls); (2) estuaries may have more introduced species due to an increased volume of shipping traffic; and (3) estuaries are closer to large conurbations and, therefore, may have had more detailed collection effort. Looking at species lists from the apparent estuarine hotspots in Fig. 4, Hypotheses 1 and 3 are supported, but the extent of support for each hypothesis varies in space. The apparent algal and molluscan hotspots in the Severn Estuary represent peaks in otherwise commonly recorded rocky shore species. These appear to reflect a $10 \mathrm{~km}$ square containing habitat otherwise rare in the estuary (one of the relevant site names is Aust Rocks). In contrast, the peak in mollusc species outside Edinburgh coincides with a Conchological Society field trip and includes records of widespread but rarely identified genera such as Brachystomia.

The most clearly defined changes in species richness between adjacent grid squares (breakpoints) occurred between the Scilly Isles and Great Britain and along the south coast of England. The Scilly Isles transition probably reflects the comparison between diverse exposed and sheltered habitats within a grid square to more uniform exposed habitat in the nearest grid square in southwest England. This large drop is there- 
fore caused by the relatively low species richness at the southwestern tip of Great Britain. These squares did not feature in the most diverse $10 \%$ of sites. Therefore, there is no contradiction with the work of Turk \& Seaward (1997). These authors found similar, if not higher, richness in southwest England compared to the Scilly Isles, but their study sites included the more species-rich areas beyond the southwestern tip of England. The breakpoint at Start Point also represents a marked decrease in species richness for algae and molluscs. Start Point is a barrier to the movement of mussel larvae (Gilg \& Hilbish 2003), and east of the point there are large areas of beach. The brown alga Bifurcaria bifurcata also has a range limit in the region of Start Point (Mieszkowska et al. 2006) and other species' range limits are also consistent with the breakpoints identified in the present study (e.g. Mieszkowska et al. 2007). The features of potential hydrographic barriers and changes in habitat type or availability are present at the other breakpoints and have been identified by Herbert et al. (2009) as key features in restricting the distributions of intertidal species. Both Beachy Head and Portland Bill lie at the boundaries of coastal process cells, regions where sediment transport processes are largely independent (Motyka \& Brampton 1993). Changes in habitat around Portland Bill include rock at the headland, but beaches to either side, particularly the extensive shingle bank to the west of Portland Head. Similarly, Beachy Head is formed by harder substrate, and likely represents better quality habitat for algae than the surrounding areas of softer bedrock.

Both species richness patterns and breakpoints are consistent with factors thought to limit the distribution of individual species. Lewis (1964) listed the unstable, erosible nature of substrata, turbidity, changes of aspect, small tidal ranges and strong currents (particularly those associated with headlands) as factors leading to limits of species ranges. Alongside broader climatic patterns, the factors listed by Lewis (1964) are consistent with the location and extent of the mesoscale patterns described in the present study. Our results support a view that much of the variability in intertidal diversity at mesoscales may be predicted from features of the physical environment (salinity, temperature, fetch; Zacharias \& Roff 2001). Features of the coastline (length and fetch variation) also seemingly affect species diversity at smaller (local) scales. Aspects yet to be considered are the turnover of species between areas of differing diversity and how the mesoscale patterns translate into variation in the function and resilience of ecological communities. The latter approach requires abundance data, and it is encouraging that preliminary analyses indicate that separation of physical and trophic influences on community structure is possible (Burrows et al. 2008).
Acknowledgements. A.J.B. was funded by a Department of Employment and Learning studentship. We are grateful to the British Phycological Society, the Conchological Society of Great Britain and Ireland and the National Museums Northern Ireland for access to high resolution records held on the National Biodiversity Network.

\section{LITERATURE CITED}

Archambault P, Bourget E (1996) Scales of coastal heterogeneity and benthic intertidal species richness, diversity and abundance. Mar Ecol Prog Ser 136:111-121

> Blanchette CA, Miner CM, Raimondi PT, Lohse D, Heady KEK, Broitman BR (2008) Biogeographical patterns of rocky intertidal communities along the Pacific coast of North America. J Biogeogr 35:1593-1607

Briggs JC (1974) Marine zoogeography. McGraw-Hill, London > Burnham KP, Anderson DR (2004) Multimodel inference: understanding AIC and BIC in model selection. Sociol Methods Res 33:261-304

Burrows MT, Harvey R, Robb L (2008) Wave exposure indices from digital coastlines and the prediction of rocky shore community structure. Mar Ecol Prog Ser 353:1-12

> Bustamante RH, Branch GM (1996) Large scale patterns and trophic structure of southern African rocky shores: the roles of geographic variation and wave exposure. J Biogeogr 23:339-351

> Crisp DJ, Southward AJ (1958) The distribution of intertidal organisms along the coasts of the English Channel. J Mar Biol Assoc UK 37:157-208

D Dutilleul P (1993) Modifying the $t$ test for assessing the correlation between two spatial processes. Biometrics 49: 305-314

Ehler C, Douvere F (2009) Marine spatial planning: a stepby-step approach toward ecosystem-based management. IOC Manual and Guides No. 53, ICAM Dossier No. 6, UNESCO, Paris

> Gaines SD, Lubchenco J (1982) A unified approach to marine plant-herbivore interactions. 2. Biogeography. Annu Rev Ecol Syst 13:111-138

Gilg MR, Hilbish TJ (2003) The geography of marine larval dispersal: coupling genetics with fine-scale physical oceanography. Ecology 84:2989-2998

> Gouhier TC, Guichard F (2007) Local disturbance cycles and the maintenance of heterogeneity across scales in marine metapopulations. Ecology 88:647-657

> Harrison S, Cornell H (2008) Toward a better understanding of the regional causes of local community richness. Ecol Lett 11:969-979

Herbert RJH, Southward AJ, Clarke RT, Sheader M, Hawkins SJ (2009) Persistent border: an analysis of the geographic boundary of an intertidal species. Mar Ecol Prog Ser 379: $135-150$

> Hillebrand H (2004) Strength, slope and variability of marine latitudinal gradients. Mar Ecol Prog Ser 273:251-267

> Hillebrand H, Blenckner T (2002) Regional and local impact on species diversity: from pattern to processes. Oecologia 132:479-491

Hiscock K, Breckels M (2007) Marine biodiversity hotspots in the UK. A report identifying and protecting areas for marine biodiversity. WWF, Godalming

Johnson JB, Omland KS (2004) Model selection in ecology and evolution. Trends Ecol Evol 19:101-108

Johnson MP, Crowe TP, McAllen R, Allcock AL (2008) Characterising the marine Natura 2000 network for the Atlantic region. Aquat Conserv 18:86-97 
Kinlan BP, Gaines SD (2003) Propagule dispersal in marine and terrestrial environments: a community perspective. Ecology 84:2007-2020

Legendre P, Legendre L (1998) Numerical ecology. Developments in Environmental Modelling 20. Elsevier Science, Amsterdam

Levin SA (1992) The problem of pattern and scale in ecology. Ecology 73:1943-1967

Lewis JR (1964) The ecology of rocky shores. English Universities Press, London

Lewis JR, Bowman RS, Kendall MA, Williamson P (1982) Some geographical components in population dynamics: possibilities and realities in some littoral species. Neth J Sea Res 16: $18-28$

Lüning K (1990) Seaweeds: their environment, biogeography and ecophysiology. John Wiley, New York

Macpherson E (2002) Large-scale species richness gradients in the Atlantic Ocean. Proc Biol Sci 269:1715-1720

Mieszkowska N, Kendall MA, Hawkins SJ, Leaper R, Williamson P, Hardman-Mountford NJ, Southward AJ (2006) Changes in the range of some common rocky shore species in Britain: a response to climate change? Hydrobiologia 555:241-251

Mieszkowska N, Hawkins SJ, Burrows MT, Kendall MA (2007) Long-term changes in the geographic distribution and population structures of Osilinus lineatus (Gastropoda: Trochidae) in Britain and Ireland. J Mar Biol Assoc UK 87:537-545

Motyka JM, Brampton AH (1993) Coastal management: map-

Accepted: May 2, 2009; Submitted: October 20, 2009; ping of littoral cells. Report SR 328. HR Wallingford, Oxford

Rangel TFLVB, Diniz-Filho JAF, Bini LM (2006) Towards an integrated computational tool for spatial analysis in macroecology and biogeography. Glob Ecol Biogeogr 15:321-327

Ricklefs RE (1987) Community diversity: relative roles of local and regional processes. Science 235:167-171

Rivadeneira MM, Fernández M, Navarrete SA (2002) Latitudinal trends of species diversity in rocky intertidal herbivore assemblages: spatial scale and the relationship between local and regional species richness. Mar Ecol Prog Ser 245:123-131

> Saunders SC, Chen JQ, Drummer TD, Gustafson EJ, Brosofske KD (2005) Identifying scales of pattern in ecological data: a comparison of lacunarity, spectral and wavelet analyses. Ecol Complex 2:87-105

Schoch GC, Menge BA, Allison G, Kavanaugh M, Thompson SA, Wood SA (2006) Fifteen degrees of separation: latitudinal gradients of rocky intertidal biota along the California Current. Limnol Oceanogr 51:2564-2585

Smith SDA (2005) Rapid assessment of invertebrate biodiversity on rocky shores: where there's a whelk there's a way. Biodivers Conserv 14:3565-3576

Turk SM, Seaward DR (1997) The marine fauna and flora of the Isles of Scilly - Mollusca. J Nat Hist 31:555-633

Willis KJ, Whittaker RJ (2002) Species diversity - scale matters. Science 295:1245-1248

Zacharias MA, Roff JC (2001) Explanations of patterns of intertidal diversity at regional scales. J Biogeogr 28:471-483

Proofs received from author(s): November 20, 2009 